\title{
Adult Liver Allocation in Eurotransplant
}

\author{
Ina Jochmans, $\mathrm{MD}, \mathrm{PhD}^{1}$ \\ Marieke van Rosmalen, $\mathrm{MD}^{2}$ \\ Jacques Pirenne, MD, $\mathrm{PhD}^{1}$ \\ Undine Samuel, $\mathrm{MD}^{2}$
}

${ }^{1}$ from the Department of Abdominal Transplant Surgery, KU Leuven, University Hospitals

Leuven, Belgium

${ }^{2}$ from the Eurotransplant International Foundation, Leiden, the Netherlands.

\section{Correspondence}

Ina Jochmans

University Hospitals Leuven

Department of Abdominal Transplant Surgery

Herestraat 49

B-3000 Leuven

Belgium

E-mail: ina.jochmans@uzleuven.be

Phone: +32-16-348727

Fax: $+32-16-348743$ 


\section{Authorship contributions}

IJ analysed the data and wrote the manuscript.

MvR, JP, and US contributed to data verification and writing of the paper.

All authors have reviewed the manuscript and approved of its submission.

\section{Disclosures}

MvR is Secretary of the Eurotransplant Liver and Intestine Advisory Committee (ELIAC).

JP is President of the Belgian Liver and Intestine Advisory Committee (BeLIAC).

US is the Medical Director of the Eurotransplant International Foundation.

\section{Funding}

There was no funding for this work.

Abbreviations

ACO, approved combined organ

DBD, donation after brain death

DCD, donation after circulatory determination of death

ELIAC, Eurotransplant Liver and Intestine Advisory Committee

HCC, hepatocellular carcinoma

HU, high urgency

pmp, per million population

T, transplantable 
Abstract

Liver allocation in Eurotransplant is complex as allocation rules need to follow not only the guidelines of the European Commission but also the specific regulations of each of the 7 Eurotransplant countries with active liver transplant programs. Thirty-eight liver transplant centers served a population of about 135 million in 2015. Around 1600 deceased donor livers are transplanted annually. The number of deceased organ donors remains stable but donor age is increasing. Nevertheless, liver utilization rates are unchanged at around $80 \%$. Donation after circulatory determination of death (DCD) increased 4-fold in the past decade. In Belgium and the Netherlands, DCDs were responsible for $30 \%$ of deceased donor liver transplant activity in 2015; Austria only occasionally transplants a DCD liver; other Eurotransplant countries do not have active DCD programs. The most frequent indications for liver transplantation are alcoholic liver disease, hepatocellular carcinoma, and viral hepatitis. Livers are allocated first internationally to high urgency status patients or those with an approved combined organ status (for a liver in combination with heart, lung, intestine, or pancreas) and then on a national basis where allocation is recipient-driven or center-driven, depending on country-specific rules. Median waiting time for an elective liver transplant was 4,4 months in 2015; high urgency status patients waited a median of 2 days for a suitable liver. Mortality on the waiting list was $18 \%$ in $2015,4 \%$ of patients were delisted because they became unfit for transplantation. One and 5-year risk unadjusted adult patient survival after transplantation is $80 \%$ and $65 \%$. 


\section{Introduction}

The Eurotransplant International Foundation, known as Eurotransplant, is a nonprofit organization that facilitates patient oriented allocation and cross-border exchange of deceased donor organs for a population of about 135 million in 8 member states of the European Union. The international collaborative framework of Eurotransplant includes all transplant centers, tissue-typing laboratories, and donor hospitals in Austria, Belgium, Croatia, Germany, Hungary, Luxembourg, the Netherlands, and Slovenia (Fig. 1). Eurotransplant manages an active waiting list of nearly 15000 people and facilitates about 6300 deceased donor organ transplants per year. ${ }^{1}$

This paper gives a short overview of the complex organization of Eurotransplant and then focuses on liver allocation to adult recipients in its member states. It also presents some key data regarding deceased organ donation and liver allocation and transplantation in Eurotransplant.

\section{History of Eurotransplant}

Eurotransplant was founded in 1967 when Jon J. van Rood sought means to match kidneys not only by $\mathrm{AB} 0$ compatibility but also by histocompatibility. ${ }^{2}$ Twelve transplant centers in Belgium, Luxembourg, and the Netherlands participated voluntarily and Eurotransplant registered the information of their kidney transplant candidates. The centers reported their donors and Eurotransplant made the best possible match for the kidneys. The outcome of kidney transplants improved dramatically ${ }^{3}$ and Eurotransplant widened its scope to other countries that wished to join the organisation and other organs. 
By 1971, Austria, West Germany, and Switzerland had joined. Switzerland withdrew from Eurotransplant, but in 1991 East Germany joined, followed by Slovenia in 1999, Croatia in 2007, and Hungary in 2013. In 2015, 71 kidney, 40 heart, 38 liver, 37 pancreas, 24 lung, and 2 intestinal programs performed transplantations and organs were procured in about 1600 donor hospitals. ${ }^{1,4}$ The number of active programs varies slightly over time, for example intestinal transplants have been performed in 10 centers between 2010-2015.

During the 1970s Eurotransplant started allocating donor livers. A few years later, services were expanded to include the allocation of heart and pancreas. Since 1987 lungs have been allocated and intestines have been exchanged since 1999. ${ }^{1}$ Since its foundation, over 200000 organs have been allocated by Eurotransplant. ${ }^{5}$

The organization of Eurotransplant

Organ donation and transplantation in member states of the European Union is regulated on a national level. National Competent Authorities have implemented the European Commission's 'Directive on standards of quality and safety of human organs intended for transplantation, ${ }^{, 6}$ - adopted by the European Parliament and Council on July $7^{\text {th }}, 2010-$ through country specific regulations. The 8 Eurotransplant member countries delegate the allocation of their deceased donor organs to Eurotransplant. Eurotransplant is not directly embedded in the national health care systems of the individual countries. The organization of the donation and transplantation procedures as well as the monitoring of transplant outcomes remains the responsibility of the national Competent Authorities.

As mediator between donor and recipient, Eurotransplant plays a key role in the management of the distribution of donor organs. Eurotransplant's organ allocation principles are based on 
the best possible match between donor organ and recipient, urgency, optimized organ utilization, overall transparency and objectivity while fully complying with the legislation of its countries. To facilitate this, the national Competent Authorities, the national scientific transplant societies, and the transplant centers actively have input in the policy and practice of Eurotransplant through representation in the Eurotransplant Board, Assembly, Council, and Advisory Committees (Fig 2). ${ }^{7}$ Best practice recommendations and policies to further improve organ allocation and transplant outcomes are continuously developed. For the liver, the Eurotransplant Liver and Intestine Advisory Committee (ELIAC) plays a central role in evaluating and optimizing liver allocation (Fig. 2). ELIAC is responsible for monitoring and optimizing the liver and intestine allocation procedures and advises the Board to approve new rules for procurement and allocation of liver and intestine. ${ }^{1}$ Eurotransplant relies on analysis of registry data detailing donor, procurement, transplantation, and posttransplant recipient outcome data in order to evaluate the allocation rules. Donor and procurement details are required for allocation purposes and therefore mandatory. Return of recipient outcome data to the Eurotransplant Registry by the individual transplant centers currently takes place on a voluntary basis. Eurotransplant strongly encourages return of outcome data but it does not have the legal authority to compel return of these data as monitoring of transplant outcomes is the responsibility of the national Competent Authorities.

\section{Legislation on deceased organ donation in Eurotransplant countries}

All Eurotransplant countries allow deceased organ donation. Most countries have an 'opt-out' system with presumed consent for deceased organ donation except the Netherlands and Germany who have an 'opt-in' system (called 'decision solution' in Germany) (Table 1).

Unlike donation after brain death (DBD), the regulation for donation after circulatory determination of death (DCD) is country specific. In the majority of countries legislation 
allows DCD donation, nevertheless, only 3 countries - Austria, Belgium, and the Netherlands - have active DCD programs and will accept DCD organs for transplantation (Table 1). In Croatia, Germany, and Hungary, DCD donation is illegal and therefore these countries are also not allowed to accept DCD organs for transplantation. In Slovenia and Luxembourg DCD is legal but no DCD programs are currently in place. These national differences have important implications for the allocation of DCD organs.

Adult liver offering and allocation rules

Eurotransplant offers deceased donor livers sequentially to 3 categories of patients based on urgency: "high urgency" (HU) status, "approved combined organ" (ACO) status, and "elective transplants". AB0-incompatible liver transplants are not allowed as long as there are suitable compatible recipients (Table 2). If no transplant center within a Eurotransplant country accepts the liver for transplantation, it can be offered outside of Eurotransplant though this only happens occasionally and specific consent from the donor or the donor family is needed. Occasionally Eurotransplant will be offered a liver from a nonEurotransplant country for similar reasons.

\section{High urgency status}

Patients presenting with acute liver failure can be granted an HU-status when they meet 1 of the following diagnostic criteria ${ }^{8}$ : (a) acute liver failure as defined by the King's College criteria $^{9}$ or the Clichy criteria $^{10}$; (b) acute graft failure within 14 days after liver transplantation (that was registered with Eurotransplant) including hepatic artery thrombosis, portal vein thrombosis, and primary nonfunction; (c) acute liver failure due to rapidly progressive Wilson's disease; (d) acute liver failure due to rapidly progressive Budd-Chiari syndrome; (e) life threatening liver trauma; (f) anhepatic state secondary to acute liver failure with toxic liver syndrome. 
The Eurotransplant Medical Staff evaluate each HU request and will grant an HU-status if the HU criteria are met. When in doubt, 2 or - in case of a split decision - 3 ELIAC members, from outside the country of the requesting center, will be contacted to advise (HU audit). HU-status patients get absolute priority and livers for these patients are offered internationally. The patient waiting the longest in the HU-status is ranked highest. Should an HU-status patient not be transplanted within 14 days after the HU-status was granted, a reevaluation will take place. At this time the clinical status of the patient and the number and details of liver offers that were turned down are audited upon which the request for HU-status will be re-affirmed or denied.

As livers for HU-status patients are offered internationally, measures to ensure a fair balance of exchange between countries are needed. When a liver is allocated to a recipient outside the donor country because of urgency rules, an 'obligation to offer' - also called a 'payback' - is generated. ${ }^{8}$ The receiving country of this liver has the obligation to offer the next available liver in the same blood group to the donor country.

\section{Approved Combined Organ status}

An ACO-status can be requested for patients in need of a liver combined with a heart, lung, intestine, or pancreas. ${ }^{8}$ Simultaneous liver-kidney transplantations are not included in the ACO category. ACO requests are evaluated by 1 ELIAC member and 1 member of the Eurotransplant Thoracic or Pancreas Advisory Committee. In case of an ACO request including the intestine, a second ELIAC member will be involved. The evaluating members must be from outside the country requesting the ACO. When an offer to an ACO-status patient is made, the 'leading' organ will initiate the match. Eurotransplant offers the heart first, followed by the lungs, liver, intestine, and pancreas; ie a patient waiting for a combined 
heart-liver transplant will receive the offer based on the profile criteria set for the heart.

ACO-status receives international priority just after HU-status patients, therefore they will generate an 'obligation to offer' when the recipient is located outside the donor country.

\section{Elective transplants}

Patients who are waiting for an elective transplant are offered a liver on a national basis. National regulations determine whether liver offering is 'recipient-driven' or 'center-driven'. When a liver cannot be placed nationally, it will be offered internationally according to specific rules.

\section{Matching of donor and recipient}

The ranking of patients at the time of a liver offer depends on the donor country, and the 'match MELD' score. AB0 blood group rules (Table 2), predefined center and donor profile criteria (age, weight, virology, split, ...) for a particular recipient, and time from listing (to rank multiple candidates with the same 'match MELD') are also taken into account when an offer is made.

The 'match MELD' corresponds to the 'lab MELD' or an 'exceptional MELD', whichever is highest. The lab MELD is derived from the classical formula, developed as the Model for End-stage Liver Disease, ${ }^{11}$ containing INR, bilirubin, and creatinine, where the maximal creatinine value is set at $4.0 \mathrm{mg} / \mathrm{dL}$. If a patient has received renal replacement therapy twice a week within a week prior to the creatinine test, a creatinine value of $4.0 \mathrm{mg} / \mathrm{dL}$ will be used in the MELD formula. To avoid the misuse of vitamin $\mathrm{K}$ antagonists to artificially increase the MELD score, the INR value is only valid if no vitamin $\mathrm{K}$ antagonists were administered within 2 weeks before determination of that INR value. In case of vitamin $\mathrm{K}$ antagonist 
therapy the last value prior to starting vitamin $\mathrm{K}$ antagonists has to be used or the vitamin $\mathrm{K}$ antagonists have to be stopped for at least 2 weeks to determine the current INR. If no INR value is known at the time of data entry in the Eurotransplant system, a value of 1.00 will be used in the MELD score calculation. The lab MELD is capped at a maximum of 40 points and needs to be recertified at prespecified intervals: a lab MELD $\geq 25$ expires after 7 days; between 19-24 after 30 days; between 11-18 after 90 days; and $\leq 10$ after 365 days. $^{8}$

In cases where the severity of the liver disease is not well reflected by the lab MELD (eg hepatocellular carcinoma, portopulmonary hypertension, polycystic liver disease, etc) an exceptional MELD can be requested. When an exceptional MELD is granted, the patient will receive MELD points that start at a fixed initial value and are upgraded at 90-day intervals. The fixed initial value depends on indication for transplantation and country-specific rules. Usually the exceptional MELD starts at the equivalent of $10 \%$ to $15 \%$ of the 90 -day predicted mortality, meaning a patients starts with an exceptional MELD of 20 or 22 . This score is then usually upgraded by $10 \%$ of the exceptional MELD every 90 days. Should the lab MELD be higher than the exceptional MELD at time of matching, the lab MELD will prevail in the match.

Country-specific lists of conditions that can be granted an exceptional MELD status are available and are regularly updated (Table 3 gives a summary). ${ }^{8}$ When predefined criteria are met, a so-called 'Standard Exception' is granted for a period of 90 days and an exceptional MELD is awarded. Before the expiry of this 90-day period, the patient's status that grants them the exceptional MELD must be reconfirmed to ensure the patient still meets the predefined criteria. 
Belgium, Germany, and the Netherlands have set up national audit groups that can assess individual requests for awarding an exceptional MELD for which there are no prespecified criteria. These are referred to as 'Non-Standard Exceptions'. As of May 2016, Croatia also has the possibility to request 'Non-Standard Exception' status through an audit group.

\section{Recipient-driven versus center-driven offering}

In Germany and the Netherlands, regular liver offering is always recipient-driven, ie an offer is made to the highest-ranking individual patient, regardless of their transplant center. When the center declines the offer for that recipient, the liver is offered to the next patient on the ranking list who might be at a different transplant center. In contrast, Austria, Croatia, Hungary, and Slovenia have a center-driven allocation system in which the liver is offered to a transplant center. The center is not obliged to accept the offer for the highest ranked patient, it can choose to allocate the liver to a lower ranked patient deemed to be a more suitable candidate by the transplant team at time of organ offer. Belgium has a mixed model with recipient-driven offers for DBD livers and center-driven offers for DCD livers (Table 1).

\section{Liver allocation for elective transplant candidates in case of recipient-driven allocation}

Livers for elective transplant candidates are offered on 3 sequential levels, starting with 'regular' allocation and moving on to 'extended' or 'rescue' allocation in case the liver was not placed at the previous level.

\section{Regular allocation}

Regular allocation includes a primary offer to the highest ranked recipient. A simultaneous 'secondary' (backup) offer is made to the second patient on the ranking list to save time. If the primary liver offer is accepted, the secondary offer will expire. If the primary offer is declined, the secondary offer will become primary and a new secondary offer will be made. 


\section{Deviation from regular allocation}

In order to avoid the loss of an organ, Eurotransplant is allowed to deviate from regular allocation in certain conditions. ${ }^{12}$ For the liver, Eurotransplant will not deviate from regular allocation until 2 hours ( 1 hour in Germany) before the planned start of the donor procedure. ${ }^{12}$ If the liver is not allocated by then, deviation from regular allocation will take place either as 'extended allocation' or 'rescue allocation'. Deviated allocation will also be started in case a recipient proves to not be transplantable after the liver has been retrieved, or in case a donor procedure needs to take place urgently because of donor hemodynamic instability.

Extended allocation means that the liver is offered simultaneously to all centers located in the country (or in 1 of the 7 donor regions in Germany ${ }^{13}$ ) of the center that holds the liver at the time extended allocation starts. A ranking list is drawn and each center has 30 min to identify 2 potential recipients. Eurotransplant combines all potential recipients in a ranking list and the liver is offered first to the recipient that has the highest overall rank.

Rescue allocation - sometimes called competitive allocation - is no longer a recipient-driven offer. The liver will be offered to the centers in the region or country of the liver and centers are allowed to select a suitable recipient on their list, regardless of their rank. ${ }^{12}$ The liver is offered on a 'first come, first served' basis. Should the liver not be accepted for transplantation, centers in a wider geographical range are contacted and - as a last possibility - centers outside Eurotransplant are contacted.

The possibility to deviate from regular allocation under the aforementioned well-defined conditions has proven important to prevent organ loss. Of all transplanted deceased donor livers, about $20 \%$ to $25 \%$ are placed through deviated allocation. In $2015,11 \%$ of livers 
transplanted into elective recipients were allocated through extended allocation, $8 \%$ through rescue allocation. ${ }^{14}$

Data and statistics

\section{Deceased organ donors in general}

In 2015, on average 15.1 deceased donors per million population (pmp) donated at least 1 organ for transplantation in the Eurotransplant region. ${ }^{15}$ There are, however, clear differences in donor rates between the Eurotransplant countries, varying from over 35 actual donors pmp to around 5 actual donors pmp (Table 1). DCD donation rates have doubled in the past decade, from $6 \%$ of all deceased organ donors in 2006 to $12 \%$ in $2015 .^{16}$ In $2015,3 \%$ of transplanted deceased donor organs in Austria, 33\% in Belgium, and 52\% in the Netherlands originated from DCD donors (Fig. 3).

Donor age has increased significantly over the past few decades and continues to increase (Fig. 4). While median deceased donor age was 35 years in 1990, this has increased to 54 years (interquartile range 23-57) in 2015. ${ }^{17}$ Nevertheless, despite the increasing donor age and with it an inevitable increase of donor co-morbidities - organ utilization has remained stable. Between 90 and $95 \%$ of all deceased donor procedures result in at least 1 organ being transplanted (Fig. 5). Organ utilization of DCDs is lower compared to DBDs (73\% versus $95 \%$ in 2015 , respectively). ${ }^{18}$

\section{Deceased liver donors}

Around 1600 liver transplantations in 38 liver transplant centers among 7 countries (Luxembourg refers its patients to Belgium or France) are performed on a yearly basis (Table 1). The majority of deceased donor livers are whole DBD grafts. Split liver transplantation 
counts for $6 \%$ of overall deceased donor liver transplant activity over the past decade. ${ }^{19}$ In the past 10 years the number of DCD liver transplants has increased 4 -fold. ${ }^{20}$ In $2015,30 \%$ of livers transplanted in Belgium and the Netherlands were DCD livers. In Austria, DCD liver transplantation is exceptional with only a few cases in the past 5 years. There are no active DCD liver transplant programs in the other Eurotransplant countries, either because the law prohibits DCD donation or programs have yet to be set up. Reasons for the disparity in DCD liver transplantation are likely multifactorial. Although DCD liver transplantation can be successful, it has not reached the degree of maturity of DBD liver transplantation. There are still many issues that can complicate the introduction of DCD liver transplantation amongst which are concerns related to increased risk of primary non function and ischemic cholangiopathy, a lack of tools allowing differentiating between transplantable and nontransplantable DCD livers, a possible erosion of DCD into the DBD pool, ethical and legal concerns, etc. $^{21}$

In 2015, 1593 deceased donor liver transplants were performed of which 126 DCDs (7.9\%) and 70 splits $(4.4 \%)$. There are no strict age restrictions for liver donation. The median deceased liver donor was 54 years (interquartile range 42-64) with $25 \%$ of transplanted livers donated by donors aged 65 years or older. ${ }^{22}$ Median donor age of DCD and DBD liver donors was 51 years (interquartile range 40-56) and 54 years (interquartile range 42-65), respectively. $^{22}$

Utilization rates for liver grafts have slightly increased over the past 10 years and currently average out at a little over $80 \%$ (Fig. 5). The increased use of donors over 65 years of age is mostly responsible for the overall increase in liver utilization. In 2006, $65 \%$ of livers from donors aged 65 years or more were transplanted. The transplantation rate of these older livers 
increased to $77 \%$ in $2015 .^{23}$ Although utilization rates for DBD livers are markedly higher compared to DCD livers ( $84 \%$ versus $56 \%$ in 2015 , respectively), ${ }^{24}$ utilization rate of DCD livers has increased from $48 \%$ to $56 \%$ in the past decade. ${ }^{8}$

\section{Urgency, allocation, and indications for liver transplantation}

Between 2007 and 2014, 13\% of liver transplantations were performed in patients with an HU-status, these include transplantation for fulminant acute liver failure, primary nonfunction, and early hepatic artery thrombosis as described above. Fewer than $1 \%$ of livers were transplanted into ACO-status patients. The majority of livers were transplanted into elective candidates. In $30 \%$ of elective cases a liver is matched on exceptional MELD points (ie 'Standard Exceptions' and 'Non-Standard Exceptions') (Table 3). In countries where liver allocation is solely center-driven, $90 \%$ of livers are allocated by lab MELD points, compared to $62 \%$ in countries where liver allocation is patient-driven (Table 4).

In the same period, the most frequent indications for elective liver transplantation were postalcoholic cirrhosis, hepatocellular carcinoma, and viral hepatitis (Fig. 6). Overall liver retransplantation rates are $10 \%$.

Median lab MELD at time of transplantation was 17 (interquartile range 11-28) in $2015 .^{25}$ In Eurotransplant countries where liver allocation is solely center-driven, the lab MELD tends to be lower than in countries where offering is primarily recipient-driven (Table 1).

Table 1 shows that countries with center-driven allocation tend to have lower rates of waitlist mortality or delisting compared to countries with recipient-driven allocation. Donor rates in these countries are also higher - which might be related to their opt-out system - and lab MELD at time of transplantation is slightly lower. 


\section{Waiting list events and outcomes after liver transplantation}

With the current allocation system and available deceased liver donors, median waiting time for an elective liver transplant was 4.4 months in $2015 .{ }^{26}$ In $2014,62 \%$ of all patients received a suitable graft within 0-5 months after listing, over $80 \%$ were transplanted within 1 year after being listed. ${ }^{27} \mathrm{HU}$-status patients wait a median of 2 days for a suitable liver graft.

During 2015, 2584 patients were removed from the waiting list because they were transplanted $(n=1725,67 \%)$, died $(n=463,18 \%)$, became unfit for transplant (tumour progression, other medical reasons) $(n=105,4 \%)$, recovered $(n=134,5 \%)$, or were delisted for other reasons $(\mathrm{n}=157,6 \%) .{ }^{28}$ On December $31^{\text {st }}, 2015,1835$ patients were active on Eurotransplant's liver waiting list. Table 1 gives an overview of waitlist mortality or delisting because of deteriorating condition per country.

One and 5-year patient survival for adult elective deceased donor transplants, transplanted between 2007 and 2014, reaches $80 \%$ and 64\% while for adult HU-status patients this is $66 \%$ and $56 \%$. These survival data are not risk-adjusted and data completeness varies from country to country. As Table 5 shows, these outcomes are on the lower side of patient survival rates reported in other European countries. Data incompleteness might contribute to potentially distorted survival data. Importantly, these outcome data are not adjusted for donor, transplant, and recipient factors that influence the chance a transplant fails. As there are difference in outcome after liver transplantation between Eurotransplant countries (eg since the introduction of MELD allocation Germany has seen a considerable change in the risk profile of listed patients, the waitlist mortality has decreased but so has posttransplant survival ${ }^{29-31}$ ), risk factors should be kept in mind when interpreting and comparing posttransplant outcomes. Furthermore, posttransplant outcomes must be set off against mortality without 
transplantation. Reporting mortality from listing as well as performing risk-adjustment for outcomes, as is the case in the $\mathrm{UK}^{32}$, could provide a much more balanced view than merely reporting waitlist mortality and posttransplant survival.

\section{Opportunities}

Eurotransplant - being responsible for allocation - requires donor, recipient, and procurement details. However, monitoring of outcome and program performance is necessary to continuously adapt the allocation rules. As the return of data on recipient outcome and graft survival are currently not mandatory, the return of these data to the Eurotransplant Registry albeit strongly encouraged by Eurotransplant - is variable.

Eurotransplant encourages not only the return of data but also the use of data. Donation and allocation data reports (for the whole of Eurotransplant or for a given country) are publicly available on the Eurotransplant website. ${ }^{33}$ Outcome data are, however, not publically available. Transplant centers have access to their center-specific graft and patient survival data compared to average national and Eurotransplant outcome. Center-specific data are only available to the given center and between-center comparison like in the USA or the UK is currently not possible. ${ }^{32,34}$ Comparison of data across Eurotransplant countries is also not possible. Survival data are not risk-adjusted and finally, the data completeness varies among Eurotransplant countries and transplant centers.

The further development of the Eurotransplant Registry would create many opportunities to improve not only the quality of organ donation and transplantation but also facilitate a better insight in the outcome of patients on the waiting list and opportunities to improve outcome after transplantation. 
Continued and optimized monitoring of waiting list and posttransplant outcome metrics and the use of risk-adjusted allocation models would provide policy makers with additional information to make informed decisions regarding allocation principles and regulations. Riskadjusted models could allow more refined prediction and monitoring of suggested and implemented allocation changes ${ }^{35,36}$ and have already been implemented in the USA and UK where they actively contribute to the evaluation and continuous improvement of the allocation systems. ${ }^{34}$

Implementation of such advanced evidence based allocation policy development needs continued and close collaborative efforts between the national Competent Authorities, the national transplant societies, the transplant centers, and Eurotransplant to optimize not only return of detailed follow-up data to the Registry but also analyses of these data and construction of predictive models for suggested allocation changes.

In addition, a detailed and complete Eurotransplant Registry would also facilitate scientific research to the benefit of all patients in need of a transplant or the already transplanted patients. Numerous registry studies from other registries have already shown the importance of registry data and how they can influence daily clinical practice. The availability of a reliable large registry in Eurotransplant would contribute to improved patient management within its own region and current data are already being used for this purpose. ${ }^{37,38}$ Furthermore, it creates the potential to facilitate the conduct of international donor management and preservation trials when primary outcome measures are captured in a registry, as was done recently by Niemann et al. ${ }^{39}$ 


\section{Conclusion}

Liver allocation in Eurotransplant is unique and complex as country specific regulations have to be followed diligently. The current liver allocation system results in high utilization rates of deceased donor organs despite increasing donor risk. However, as donor and recipient characteristics constantly change, allocation policies need continuous optimization. Furthermore, as there is still significant mortality on the waiting list there is scope for continued improvement. Advanced analysis of waiting list and outcome metrics together with risk adjustment would allow refined evidence-based decisions to optimize the allocation policies that are focused on organ utilization, urgency, the best possible match, and the best possible outcome.

\section{Acknowledgments}

The data provided in this work represents the contribution of all those involved in donation, procurement, and transplantation in Eurotransplant.

All data presented were derived from the Eurotransplant registry and we are grateful to the Eurotransplant database managers for providing them, in particular Agita Strelniece and Erwin de Vries. Data and figures were reproduced with permission (media req 300.2016). 


\section{References}

1. Eurotransplant. Eurotransplant International Foundation. http://www.eurotransplant.org. Updated 2016. Accessed May 2016.

2. van Rood JJ, Freudenberg J, van Leeuwen A, Schippers HM, Zweerus R, Terpstra JL. Eurotransplant. Transplant Proc. 1971;3(1): 933-941.

3. Persijn GG, Gabb BW, van Leeuwen A, Nagtegaal A, Hoogeboom J, van Rood JJ. Matching for HLA antigens of A, B, and DR loci in renal transplantation by Eurotransplant. Lancet. 1978;1(8077): 1278-1281.

4. Eurotransplant. Annual Report 2015. Leiden, the Netherlands: Eurotransplant Internation Foundation. http://www.eurotransplant.org. Published 2015. Accessed December 30th, 2016. 5. Transplants in Eurotransplant, 1967 to 2016 (Apr), by donor type, by organ: 2280P_All ET : 06.05.2016 : counting for each organ type (double lung/kidney=1).

6.

European

Commission.

http://ec.europa.eu/health/blood_tissues_organs/organs/index_en.htm. Updated 2016 . Accessed May 2016.

7. Eurotransplant. Introduction, version 4, October 2014 of the Eurotransplant Manual . http://eurotransplant.org/cms/index.php?page=et_manual__Accessed Decmeber 30 ${ }^{\text {th }}, 2016$.

8. Eurotransplant. Liver Allocation System (ELAS), version 5, May 2016 of the Eurotransplant Manual http://eurotransplant.org/cms/index.php?page=et_manual__Accessed Decmeber $30^{\text {th }}, 2016$.

9. O'Grady JG, Alexander GJ, Hayllar KM, Williams R. Early indicators of prognosis in fulminant hepatic failure. Gastroenterology. 1989;97(2): 439-445.

10. Bernuau J, Goudeau A, Poynard T, et al. Multivariate analysis of prognostic factors in fulminant hepatitis B. Hepatology. 1986;6(4): 648-651.

11. Malinchoc M, Kamath PS, Gordon FD, Peine CJ, Rank J, ter Borg PC. A model to predict 
poor survival in patients undergoing transjugular intrahepatic portosystemic shunts. Hepatology. 2000;31(4): 864-871.

12. Eurotransplant. Allocation General, version 2.87, June 17, 2015 of the Eurotransplant Manual. http://eurotransplant.org/cms/index.php?page=et_manual__Accessed Decmeber $30^{\text {th }}$, 2016.

13. Deutsche Stiftung Organtransplantation - German Organ Transplantation Foundation. http://www.dso.de/dso/struktur-der-dso/regionen.html.Accessed Decmeber 30 $0^{\text {th }}, 2016$.

14. Liver-only transplants (deceased donor) in All ET, by year, by characteristic. 2072P_All ET_liver : 07.01.2016.

15. Deceased donors used in 2015 , per million population, by donor country, by organ. 1033P_2015:25.03.2016.

16. Deceased donors used in All ET, by year, by donor type \% DBD/DCD. 1233E_All ET_all organs : 18.03.2016.

17. Deceased donors used in All ET, median age, by year, by organ used. 1085P_All ET : 24.05.2016.

18. Deceased donors (any organ) in All ET, usage rate, by year, by donor type DBD/DCD. 1231E_All ET_all organs : 24.05.2016.

19. Liver transplants in All ET, by year, by donor type, by organ combination. 2052P_All ET_liver : 07.01.2016.

20. Non-heartbeating donation in All ET, by year, by organ combination, by transplant country. 1177P_All ET : 07.01.2016.

21. Muiesan P. Liver transplantation using non-heart-beating donors. In: Talbot D, D'Alessandro AM, eds. Organ donation and transplantaton after cardiac death. Oxford, United Kingdom: Oxford University Press; 2009:213-229.

22. Deceased donors (DBD) used in All ET, age distribution, by year, by organ used. 
1087P_All ET : 02.06.2016.

23. Deceased donors used in All ET, by year, by organ, by age. 1102P_All ET : 07.01.2016.

24. Deceased liver donors in All ET, usage rate, by year, by donor type DBD/DCD. 1231E_All ET_liver : 24.05.2016.

25. Liver transplants (deceased donor), by MELD type, by year, by country. x16_0005-2liver_liver : 20.01.2016.

26. Liver transplant (deceased donor) recipients in All ET, median time to transplant, by year, by urgency at transplant. 2393P_liver : 18.03.2016 : months since put on waiting WL.

27. Eurotransplant. Annual Report. Leiden, the Netherlands: Eurotransplant Internation Foundation. http://www.eurotransplant.org. Updated 2016. Accessed Decmeber 30 2016.

28. Waiting list removals in All ET, by year, by organ, by reason. 4502P_All ET : 07.01.2016.

29. Schlitt HJ, Loss M, Scherer MN, et al. Current developments in liver transplantation in Germany: MELD-based organ allocation and incentives for transplant centres. $Z$ Gastroenterol. 2011;49(1): 30-38.

30. Weismuller TJ, Fikatas P, Schmidt J, et al. Multicentric evaluation of model for end-stage liver disease-based allocation and survival after liver transplantation in Germany--limitations of the 'sickest first'-concept. Transplant Int. 2011;24(1): 91-99.

31. Quante M, Benckert C, Thelen A, Jonas S. Experience Since MELD Implementation: How Does the New System Deliver? Int J Hepatology. 2012;2012: 264015.

32. NHS Blood and Transplant. Annual Report on Liver Transplantation. http://www.odt.nhs.uk/pdf/organ_specific_report_liver_2015.pdf. Published September 2015. Accessed Decmeber 30 ${ }^{\text {th }}, 2016$.

33. Eurotransplant. Statistics Report Library. http://statistics.eurotransplant.org/__Updated 2016. Accessed Decmeber $30^{\text {th }}, 2016$. 
34. Scientific Registry or Transplant Recipients. http://www.srtr.org/default.aspx. Updated 2016. Accessed Decmeber $30^{\text {th }}, 2016$.

35. Stewart DE, Kucheryavaya AY, Klassen DK, Turgeon NA, Formica RN, Aeder MI. Changes in Deceased Donor Kidney Transplantation One Year After KAS Implementation. Am J Transplant. 2016;16(6): 1834-1847.

36. Gentry SE, Chow EK, Massie A, et al. Liver sharing and organ procurement organization performance under redistricted allocation. Liver Transpl. 2015;21(8): 1031-1039.

37. Gyori GP, Silberhumer GR, Rahmel A, et al. Impact of dynamic changes in MELD score on survival after liver transplantation - a Eurotransplant registry analysis. Liver Int. 2016;36(7): 1011-1017.

38. Heylen L, Pirenne J, Samuel U, et al. The impact of anastomosis time during kidney transplantation on graft loss: A Eurotransplant cohort study. [published online ahead of print September 4, 2016]. Am J Transplant. DOI: 10.1111/ajt.14031.

39. Niemann CU, Malinoski D. Therapeutic Hypothermia in Deceased Organ Donors and Kidney-Graft Function. N Engl J Med. 2015;373(27): 2687.

40. Liver waiting list registrations, by year, by country. 4001P_liver : 25.03.2016.

41. Liver transplants (deceased donor), per million population, by year, by country. 2271P_liver : 25.03.2016.

42. Liver waiting list removals, by year, by country, by reason. 4501P_liver : 25.03.2016.

43. Liver transplants (deceased donor), median MELD scores, by year, by country. x16_00052-liver_liver.

44. Valutazione di qualità dell'attività di trapianto (periodo 2000-2013), Ministero della Salute. $\quad$ http://www.trapianti.salute.gov.it/cnt/cntDettaglioMenu.jsp?id=73\&area=cntorgani \&menu=menuPrincipale $\&$ sotmenu=qualita\&label=moq\&livello=1 Published 2016. Accessed Decmeber $30^{\text {th }}, 2016$. 
45. Le rapport médical et scientifique de l'Agence de la biomédecine - Le rapport médical et scientifique du prélèvement et de la greffe en France. http://www.agencebiomedecine.fr/annexes/bilan2014/donnees/organes/05-foie/synthese.html. Updated 2016. Accessed Decmeber 30 ${ }^{\text {th }}, 2016$.

46. Spanish Liver Transplant Registry - Registro Espanol de trasplante hepatico, memoria de resultados 2014. http://www.sethepatico.org. Updated 2016. Accessed Decmeber 30 ${ }^{\text {th }}, 2016$.

47. Donors used in Austria, by year, by donor type. 1092P_Austria : 25.03.2016.

48. Donors used in Belgium, by year, by donor type. 1092P_Belgium : 25.03.2016.

49. Donors used in the Netherlands, by year, by donor type. 1092P_Netherlands : 25.03.2016. 
Figure legends

Fig. 1: Eurotransplant member states: Austria, Belgium, Croatia, Germany, Hungary, Luxembourg, the Netherlands, and Slovenia.

Fig. 2: Organizational chart of Eurotransplant

ET, Eurotransplant; ELIAC; Eurotransplant Liver and Intestine Advisory Committee; EPAC, Eurotransplant Pancreas / Islets Advisory Committee; ETEC, Eurotransplant Ethics Committee; EThAC, Eurotransplant Thoracic Advisory Committee; ETKAC, Eurotransplant Kidney Advisory Committee; FC, Financial Committee; ISWG, Information Services Working Group, OPC, Organ Procurement Committee; rep, representative; TTAC, Tissue Typing Advisory Committee. Adapted from the Eurotransplant Manual. ${ }^{7}$

Fig. 3: Evolution of transplanted organs donated after circulatory determination of death in Austria, Belgium, and the Netherlands as percentage of total deceased donor numbers between 2006 and 2015. Based on data from the Eurotransplant Registry. ${ }^{18,47-49}$

Fig. 4: Evolution of median deceased donor age in Eurotransplant between 1990 and 2015. Based on data from the Eurotransplant Registry. ${ }^{23}$

Fig. 5: Utilization rate of reported deceased donors in Eurotransplant between 2006 and 2015. Based on data from the Eurotransplant Registry. ${ }^{2}$

Fig. 6: Indications for adult elective liver transplantation in 2015. 
Figure 1

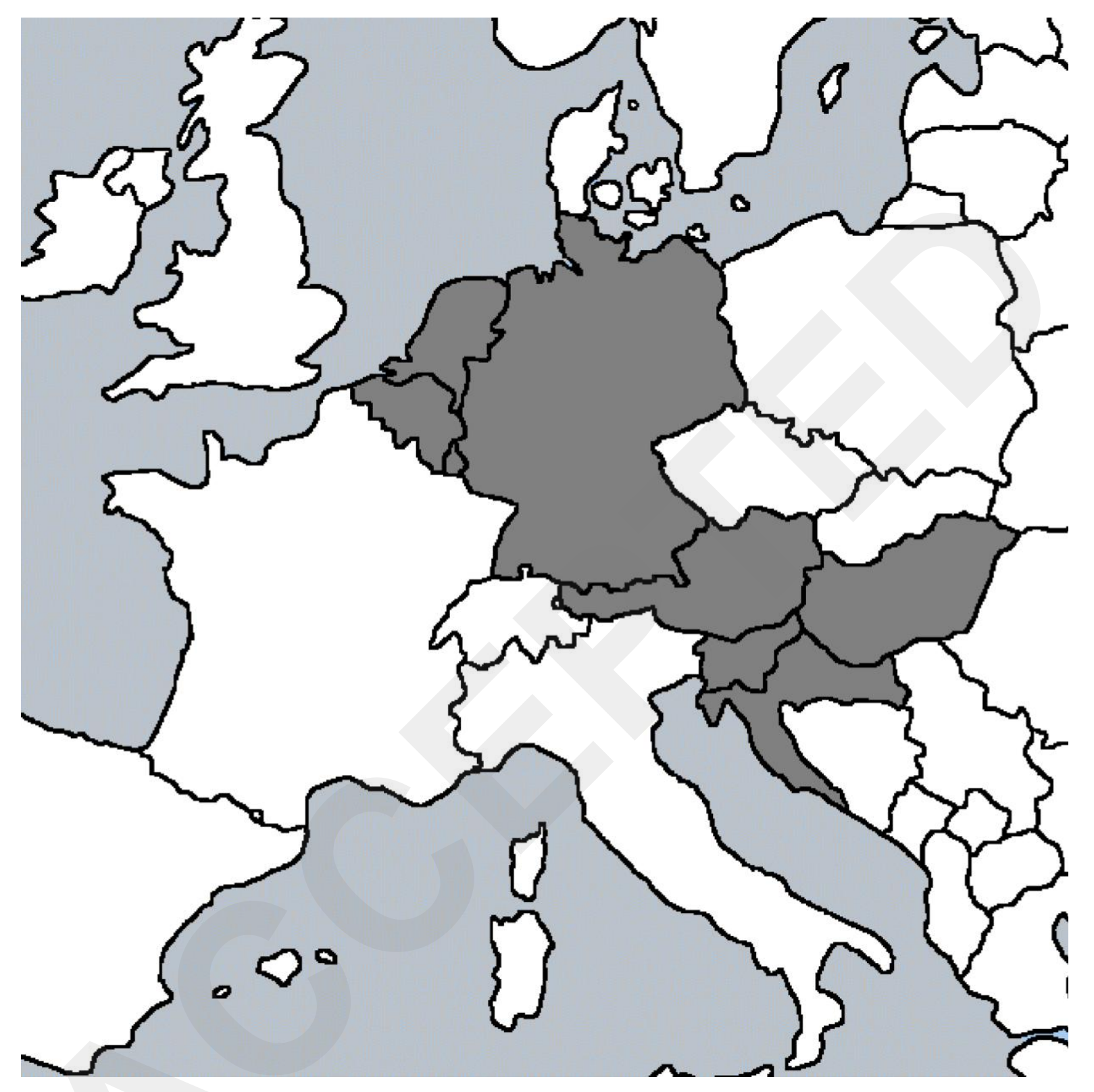


Figure 2

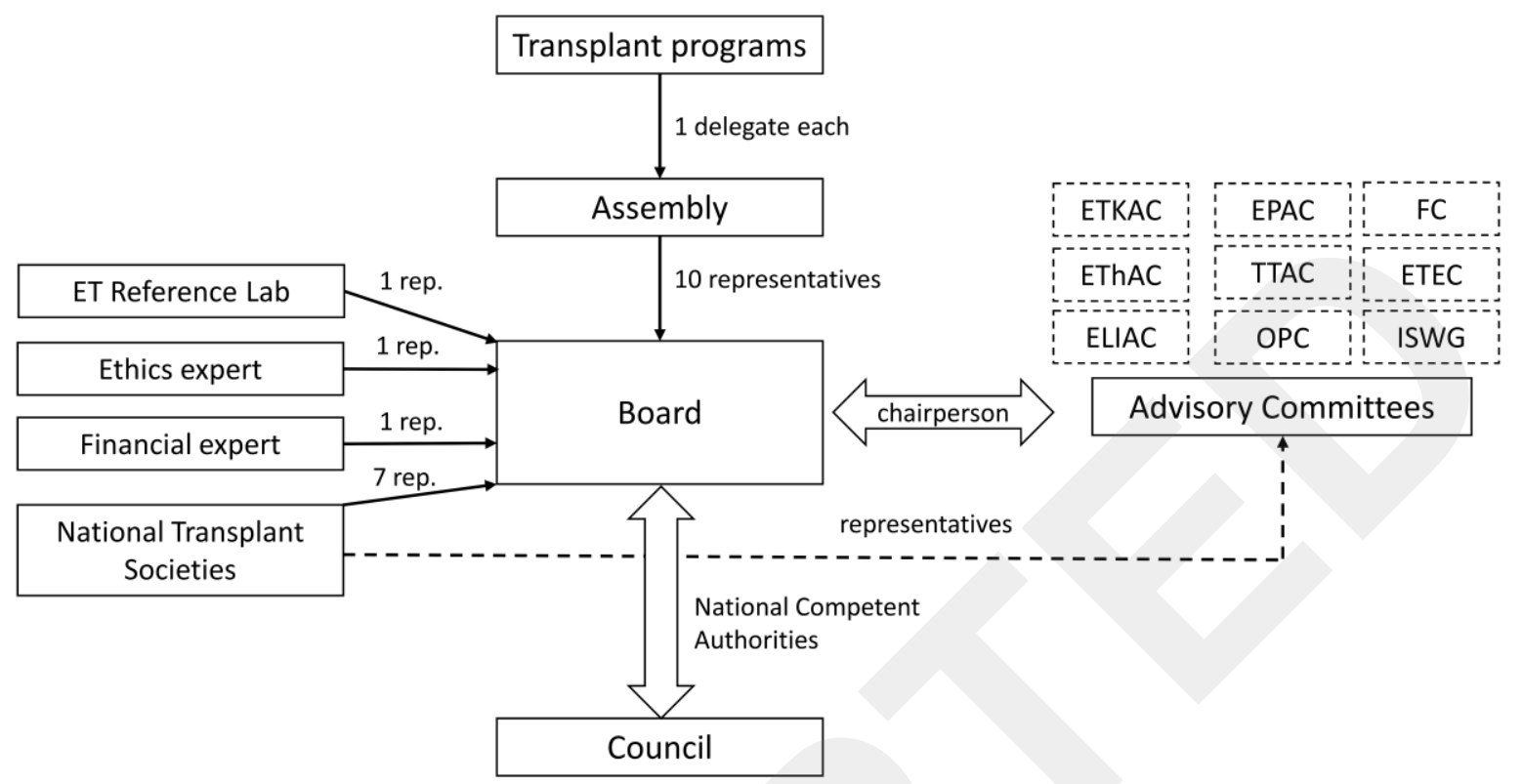


Figure 3

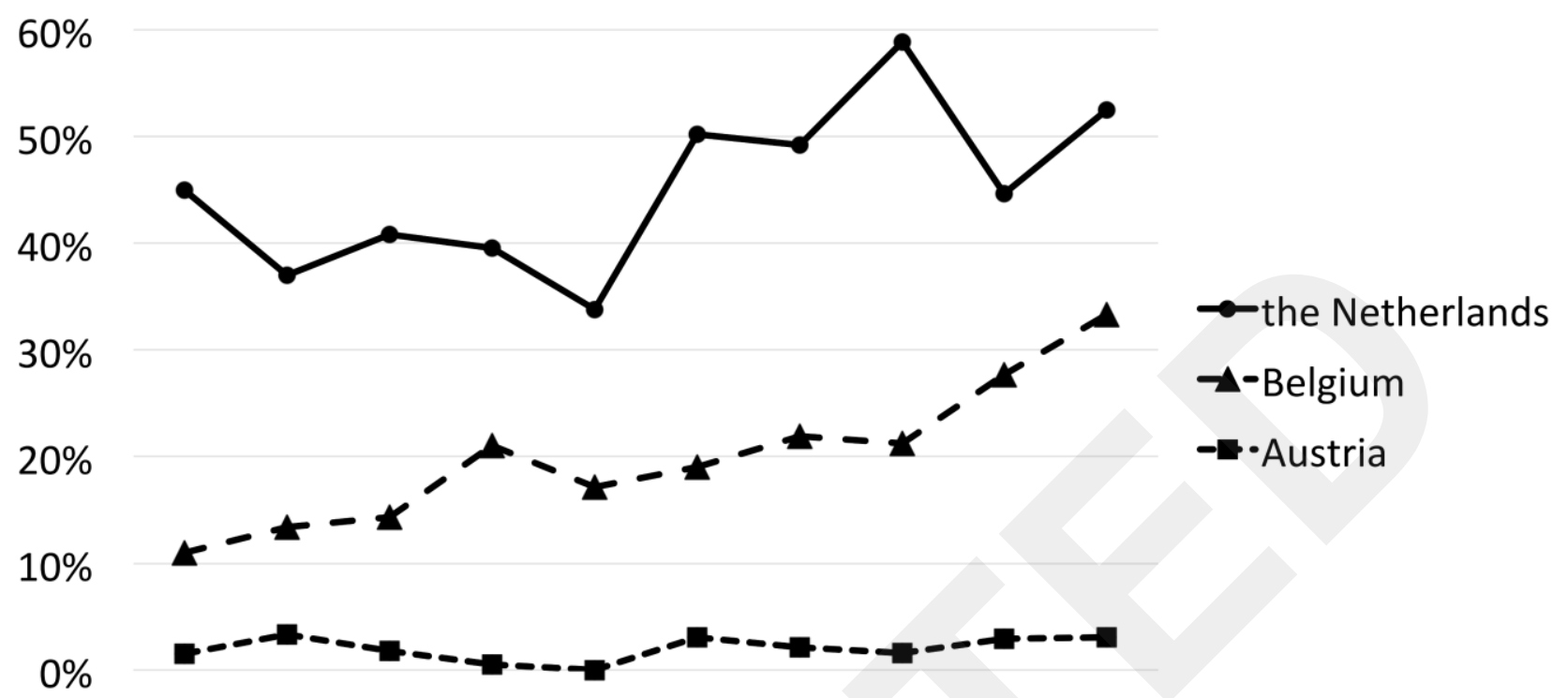

2006200720082009201020112012201320142015 
Figure 4

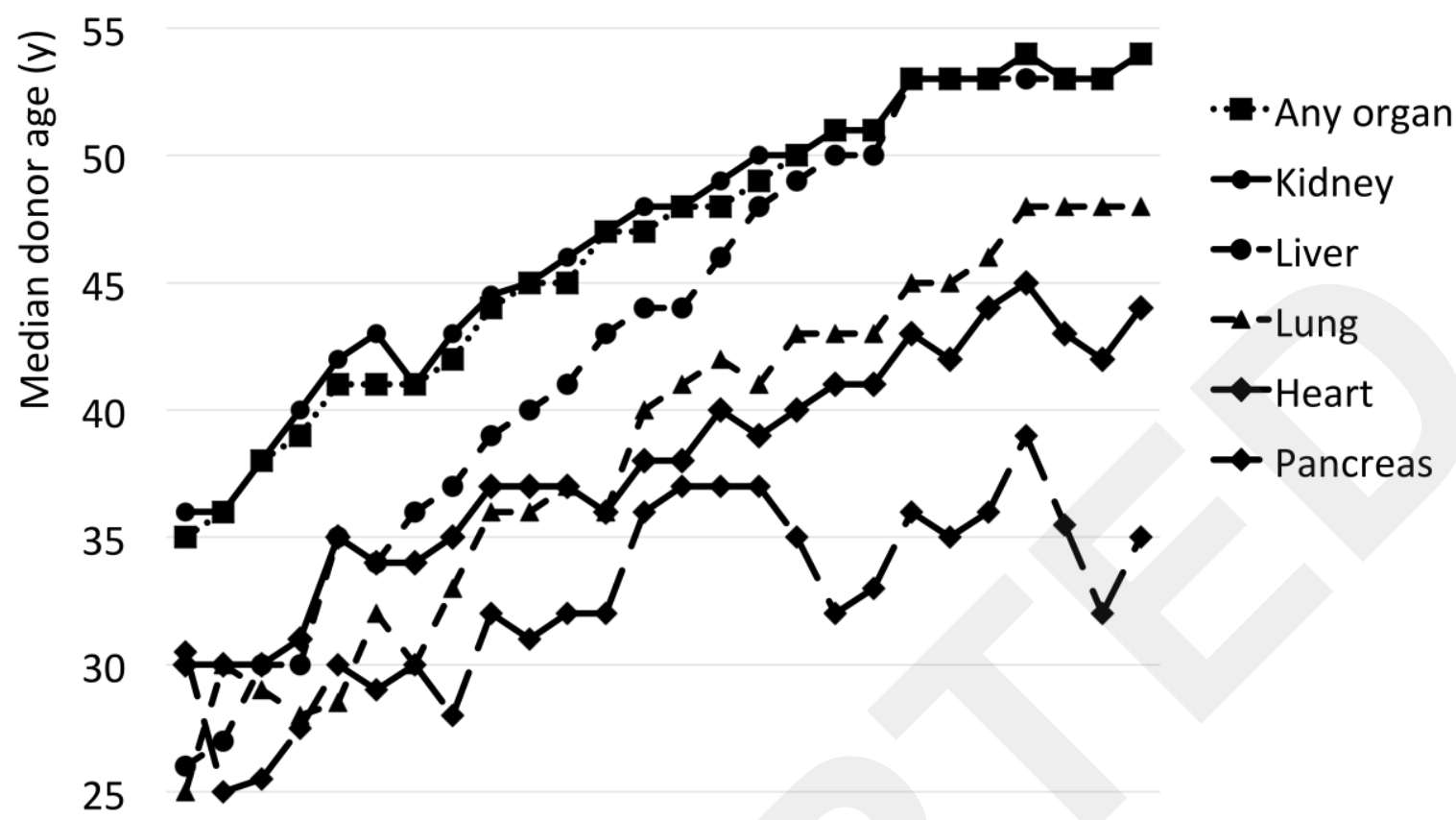

20

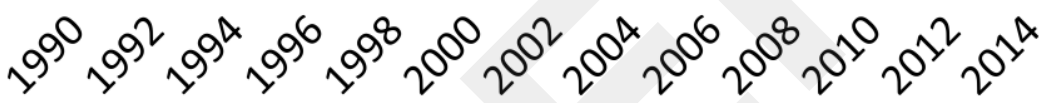


Figure 5

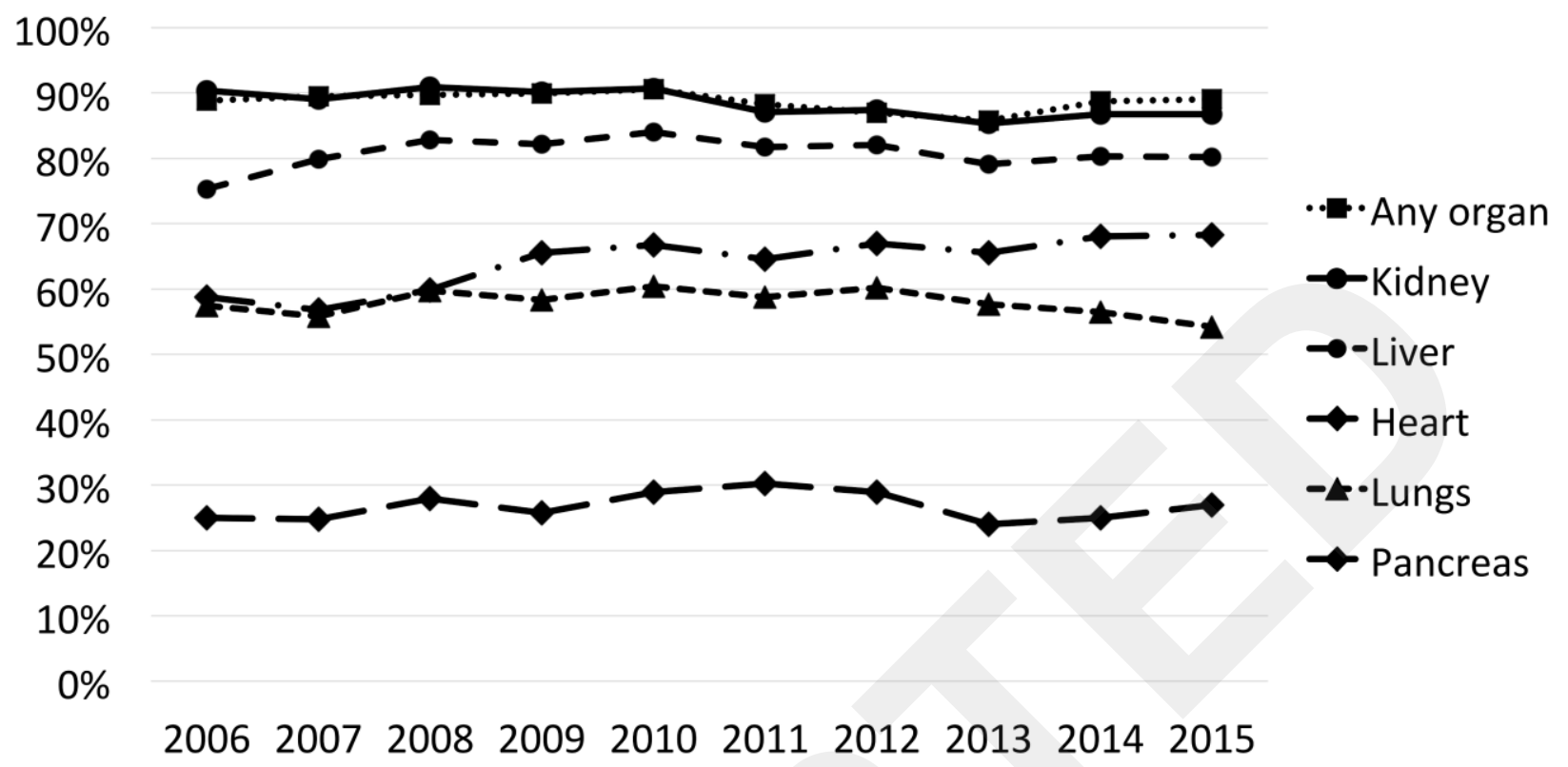


Figure 6

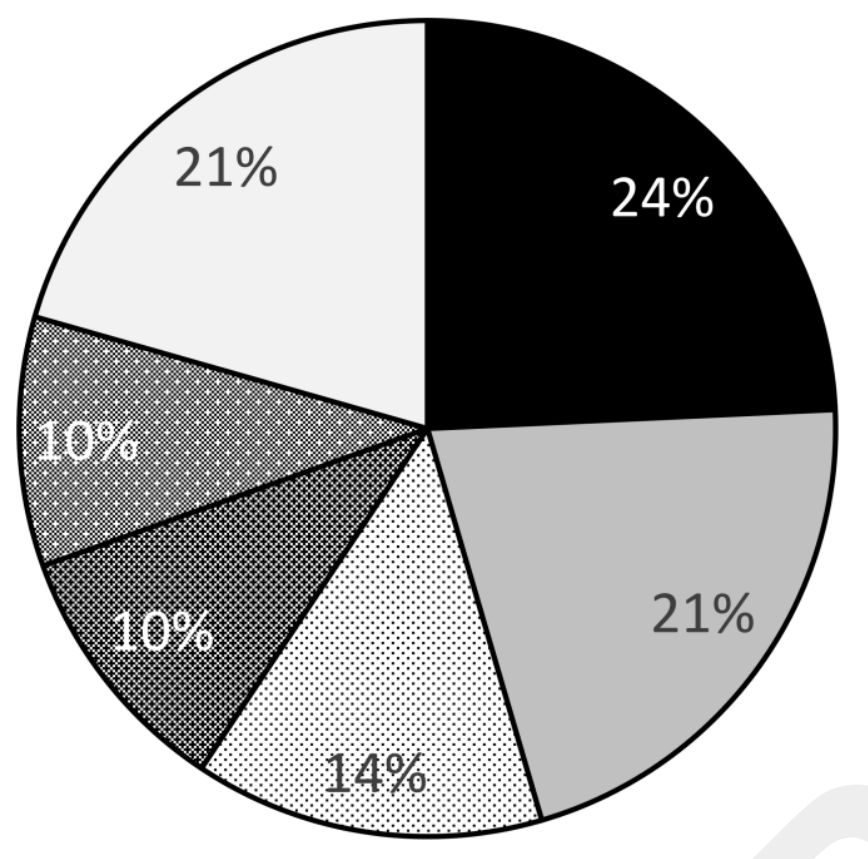

- Post-alcohol

$\square \mathrm{HCC}$

圆 Viral hepatitis

圆 Cholestatic disease

$\square$ Retransplant

$\square$ Other 
Table 1 Overview of legislation for organ donation, deceased donor types, type of liver allocation, number of active liver transplant centers, donation, waitlist registrations, and liver transplantation rates and median lab MELD at time of liver transplant in the 8 member states of Eurotransplant in 2015.

\begin{tabular}{|c|c|c|c|c|c|c|c|c|c|}
\hline Country & Legislation $^{7}$ & Donor types & Liver allocation & $\begin{array}{c}\text { Liver transplant } \\
\text { centers }^{4}\end{array}$ & $\begin{array}{c}\text { Donor rate } \\
(\mathrm{pmp})^{15}\end{array}$ & $\begin{array}{l}\text { Waitlist } \\
(\mathrm{pmp})^{40}\end{array}$ & $\begin{array}{c}\text { Liver } \\
\text { transplants } \\
\text { (pmp) }^{41}\end{array}$ & $\begin{array}{c}\text { Died or unfit } \\
\text { while waiting } \\
(\%)^{42}\end{array}$ & $\begin{array}{c}\text { Lab } \\
\text { MELD }^{43}\end{array}$ \\
\hline Austria & Opt-out & $\begin{array}{c}\text { DBD } \\
\text { DCD (active) }\end{array}$ & Center driven & 3 & 22.9 & 20.8 & 16.4 & $17(13+4)$ & $\begin{array}{c}15 \\
(12-22)\end{array}$ \\
\hline Belgium & Opt-out & $\begin{array}{c}\text { DBD } \\
\text { DCD (active) }\end{array}$ & $\begin{array}{c}\text { Recipient (DBD), } \\
\text { Center driven (DCD) }\end{array}$ & 6 & 28.0 & 35.1 & 22.3 & $19(16+3)$ & $\begin{array}{c}16 \\
(10-27)\end{array}$ \\
\hline Croatia & Opt-out & DBD & Center driven & 2 & 37.6 & 37.2 & 32.9 & $8(7+1)$ & $\begin{array}{c}17 \\
(14-22)\end{array}$ \\
\hline Germany & Opt-in & DBD & Recipient driven & 22 & 10.6 & 18.3 & 10.4 & $26(22+4)$ & $\begin{array}{c}19 \\
(12-32)\end{array}$ \\
\hline Hungary & Opt-out & DBD & Center driven & 1 & 17.7 & 12.2 & 9.0 & $19(18-1)$ & $\begin{array}{c}13 \\
(11-18)\end{array}$ \\
\hline Luxembourg & Opt-out & $\begin{array}{c}\text { DBD } \\
\text { DCD (not active) }\end{array}$ & - & 0 & 5.3 & - & - & - & - \\
\hline $\begin{array}{c}\text { the } \\
\text { Netherlands }\end{array}$ & Opt-in & $\begin{array}{c}\text { DBD } \\
\text { DCD (active) }\end{array}$ & Recipient driven & 3 & 15.7 & 12.7 & 8.8 & $20(13+7)$ & $\begin{array}{c}18 \\
(12-25)\end{array}$ \\
\hline Slovenia & Opt-out & $\begin{array}{c}\text { DBD } \\
\text { DCD (not active) }\end{array}$ & Center driven & 1 & 25.7 & 17.9 & 11.6 & $17(14+3)$ & $\begin{array}{c}16 \\
(12-22)\end{array}$ \\
\hline
\end{tabular}

Luxembourg does not have a liver transplant center and refers patients to Belgium or France.

DBD, donation after brain death; DCD, donation after circulatory determination of death; MELD, model of end stage liver disease (presented as median and interquartile range); pmp, per million population. 
Table 2 ABO blood group rules for adult (donor weight $\geq 46 \mathrm{~kg}$ ) donor liver allocation in Eurotransplant.

\section{Compatibility type}

\begin{tabular}{llll} 
Donor blood group & type 1 & type 2 & Full \\
\hline$A$ & $A$ and $A B$ & $A$ and $A B$ & $A$ and $A B$ \\
$B$ & $B$ and AB & B and AB & B and AB \\
$A B$ & $A B$ & $A B$ & $A B$ \\
0 & B, and 0 & 0 & $A, B, A B$, and 0 \\
Eligible recipients & HU-status; & Elective with MELD<30 & ACO-status; \\
& Elective with MELD $\geq 30$ & & $*$, DCD Belgium
\end{tabular}

* In non-German countries, a liver that has not been allocated nationally according to type 1 or type 2 compatibility will be offered again at full compatibility before the liver is offered internationally to elective candidates. 
Table 3 Summary of indication that can be granted a Standard Exception status in Eurotransplant. Specific conditions need to be met and these can vary slightly between countries. Detailed information is available in the Eurotransplant Manual. ${ }^{8}$

\begin{tabular}{|c|c|c|c|c|c|c|c|}
\hline & Austria & Belgium & Croatia & Germany & Hungary & the Netherlands & Slovenia \\
\hline Biliary sepsis & & & $\mathrm{x}$ & $x$ & & & $\mathrm{x}$ \\
\hline Cholangiocarcinoma & $x$ & & $x$ & $x$ & & & $x$ \\
\hline Cystic fibrosis & $x$ & $x$ & $x$ & $x$ & & & $x$ \\
\hline Familial Amyloidotic Polyneuropathy & $x$ & $x$ & $x$ & $x$ & & $x$ & $x$ \\
\hline Hepatic hemangioendothelioma & $x$ & $x$ & $x$ & $x$ & & & $x$ \\
\hline Hepatocellular carcinoma & $x$ & $x$ & $x$ & $x$ & & $\mathrm{x}$ & $\mathrm{x}$ \\
\hline Hepato-pulmonary syndrome & $x$ & $x$ & $x$ & $x$ & & $x$ & $x$ \\
\hline Hereditary hemorrhagic teleangiectasia & $x$ & $x$ & $x$ & $x$ & & & $x$ \\
\hline Non-metastatic hepatoblastoma & $x$ & $x$ & $x$ & $x$ & $x$ & $x$ & $x$ \\
\hline Persistent hepatic dysfunction post liver transplantation & $x$ & $x$ & $x$ & $x$ & & & $x$ \\
\hline Polycystic Liver Disease & $x$ & $x$ & $x$ & $x$ & & $x$ & $x$ \\
\hline Porto-pulmonary hypertension & $x$ & $x$ & $x$ & $x$ & & $x$ & $x$ \\
\hline Primary Hyperoxaluria Type 1 & $x$ & $x$ & $x$ & $x$ & & $x$ & $x$ \\
\hline Primary sclerosing cholangitis & & & $x$ & $x$ & & & $x$ \\
\hline Urea cycle disorder / organic acidemia & $x$ & $x$ & $x$ & $x$ & $x$ & $x$ & $x$ \\
\hline
\end{tabular}


Table 4 Type of MELD score on the basis of which a liver was allocated to its recipient in 2015

\begin{tabular}{lccc}
\hline & All of Eurotransplant & $\begin{array}{c}\text { Countries with patient } \\
\text { driven allocation* }\end{array}$ & $\begin{array}{c}\text { Countries with center- } \\
\text { driven allocation** }\end{array}$ \\
\hline Lab MELD & $70 \%$ & $62 \%$ & $90 \%$ \\
SE MELD & $27 \%$ & $33 \%$ & $10 \%$ \\
NSE MELD & $3 \%$ & $5 \% \wedge$ & $\wedge$ \\
\hline
\end{tabular}

* Belgium, Germany, and the Netherlands. In Belgium, DCD liver offers are center-driven

** Austria, Croatia, Hungary, and Slovenia

$\wedge$ NSE-audit groups are active in Belgium, Germany, and the Netherlands. Croatia set up an NSE audit group in 2016.

MELD, model of end-stage liver disease; NSE, non-standard exception; SE, standard exception 
Table 5 One and 5 year patient survival in different European Countries

\begin{tabular}{lllll}
\hline Country & Period & 1y & 5y & Comment \\
\hline Eurotransplant & $2007-2014$ & $80.0 \%$ & $64.0 \%$ & adult elective, unadjusted \\
& & $65.1 \%$ & $55.5 \%$ & adult urgent \\
\hline UK $^{32}$ & $01 / 04 / 2005-$ & $92.4 \%$ & $80.1 \%$ & adult elective and first, unadjusted \\
& $31 / 03 / 2015$ & $90.1 \%$ & $79.8 \%$ & super-urgent \\
\hline Italy $^{44}$ & $2000-2013$ & $85.8 \%$ & $74.0 \%$ & adult, all \\
\hline France $^{45}$ & $1993-2013$ & $85.5 \%$ & $73.5 \%$ & elective \\
& & $72.7 \%$ & $66.5 \%$ & urgent \\
& & & & \\
\hline Spain $^{46}$ & $1991-2014$ & $86.4 \%$ & $73.3 \%$ & elective \\
& & $76.0 \%$ & $69.7 \%$ & urgent \\
& & & &
\end{tabular}

